\title{
Rupture of pulmonary artery aneurysm associated with persistent ductus arteriosus
}

\author{
MICHAEL COLEMAN, DAVID SLATER, ROBIN BELL
}

From the Departments of Clinical Pharmacology and Histopathology, Hallamshire Hospital, Sheffield, and Scunthorpe General Hospital

SUMMARY Fatal haemopericardium occurred in a 14-year-old boy after rupture of a pulmonary artery aneurysm. Persistent ductus arteriosus with severe pulmonary hypertension was confirmed by cardiac catheterisation when he was 4 weeks old. Attempted closure of the ductus at 4 years had not been possible because of apparent high pulmonary resistance. Exercise tolerance had been good enough to permit competitive horse riding up to the day of death. Light and electron microscopy showed widespread cystic medionecrosis of the elastic pulmonary arteries.

\section{Case report}

This boy was born at term, weighing $3235 \mathrm{~g}$, to a 27-year-old woman. She had been in contact with rubella when two months pregnant. After delivery he was noted to be mildly cyanosed with only the right upper quadrant of the body being pink. During the first day the left upper quadrant also became pink. Initially his general condition was good but within a week feeding had deteriorated. By the age of 10 days there was evidence of heart failure in the form of hepatic enlargement and dyspnoea, but digitalisation, low-sodium diet, and oxygen led to some improvement. At 4 weeks, a pansystolic murmur maximal in the second and third left intercostal spaces was audible with a diastolic component. Chest $x$-ray film showed cardiomegaly and an electrocardiogram suggested right ventricular dominance. Right heart catheterisation at this time (Table) showed severe pulmonary hypertension and biplane cineangiocardiography from the pulmonary trunk showed a persistent ductus arteriosus, though there was no evidence of left-to-right shunt on oximetry (Table). The femoral pulses were barely palpable and retrograde aortography at 6 weeks suggested the possibility of a preductal coarctation, though the proximal to distal pressure drop was minimal (Table). Surgical intervention at this time was considered too risky.

During the next four years he had occasional chest infections, but after some delay gained weight and developed normally. He was able to run and
Table Cardiac catheter data ${ }^{\star}$

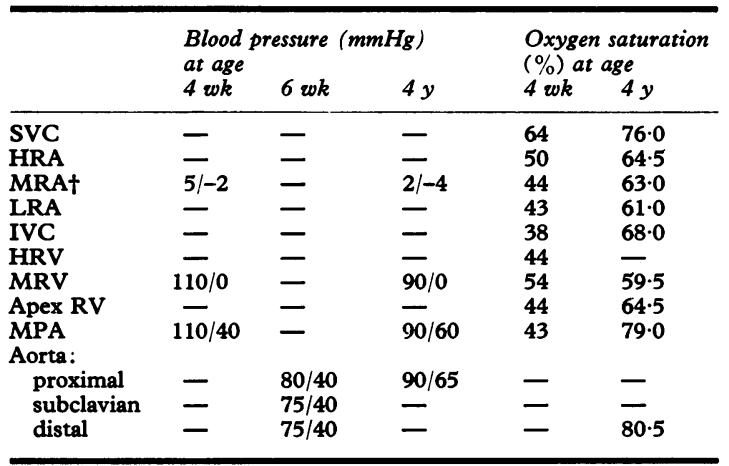

SVC, superior vena cava; HRA, high right atrium; MRA, midright atrium; LRA, low right atrium; IVC, inferior vena cava; HRV, high right ventricle; MRV, mid-right ventricle; MPA, main pulmonary artery.

*Performed under sedation and local anaesthesia. No supplementary oxygen administered.

tOnly two atrial wave forms discernible because of tachycardia.

play with other children and developed only mild dyspnoea on moderate exercise, but sometimes became cyanosed on crying. At 4 years of age the femoral pulses were easily palpable and there was no clubbing or cyanosis. There was now clinical evidence of cardiomegaly with a displaced apex beat and the sternum could be seen to bulge. A basal pansystolic murmur (grade 4) was accompanied by a thrill and a diastolic murmur (grade 1) was present. The second sound in the pulmonary area was loud 
but normally split; an electrocardiogram showed right ventricular hypertrophy. At repeat cardiac catheterisation, a catheter was passed from the right ventricle to the pulmonary artery and through the patent ductus into the descending aorta. Pulmonary and systemic pressures were almost equal and oximetry provided evidence of bidirectional shunting (Table).

Although angiocardiography was not repeated, the diagnosis was now considered to be persistent ductus arteriosus with severe pulmonary hypertension, without evidence of coarctation. In view of the poor prognosis without surgery an attempt was made to close the ductus. At thoracotomy the ductus $(0.7 \mathrm{~cm}$ diameter) was clamped for 20 minutes. During this time the aortic pressure fell by 20 $\mathrm{mmHg}$, the aortic and pulmonary artery pressures remained equal at $105 . \mathrm{mmHg}$, and cyanosis occurred. On release of the clamp the aortic pressure rose to $125 \mathrm{mmHg}$ and tissue oxygenation improved. These findings were considered consistent with a state of probably irreversible high pulmonary resistance and it was thought unreasonable to divide the ductus.

Subsequent development was unremarkable and an electrocardiogram and chest $x$-ray film taken when aged 11 is shown in Fig. 1 and Fig. 2a. At 13 years there was slight cyanosis at rest and an early diastolic murmur suggestive of pulmonary regurgitation. However, there was no effort intolerance and during the year before his death he won 32 cups for showjumping. On the day of his death, aged 14 years 4 months, he won another riding competition without dyspnoea or fatigue, but 20 minutes after his last ride he collapsed and died.

\section{NECROPSY}

External examination showed neither clubbing nor stigmata of Marfan's syndrome. The pericardial cavity was tense and distended with $550 \mathrm{ml}$ fresh blood originating from a $4 \mathrm{~cm}$ linear tear in the pulmonary artery (Fig. 2b). The tear started $0.5 \mathrm{~cm}$ above the pulmonary valve in an area of fusiform aneurysmal thinning $8 \mathrm{~cm}$ in length and $12 \mathrm{~cm}$ at its maximal circumference.

A persistent ductus arteriosus connected the main pulmonary artery and the descending aorta and measured $0.8 \mathrm{~cm}$ in diameter and $1.0 \mathrm{~cm}$ in length before fixation. The right and left ventricles were hypertrophied (140 and $310 \mathrm{~g}$, respectively). The remainder of the heart and the aorta appeared normal, with no coarctation.

On light microscopy, the tunica media of the aneurysm contained numerous pools of acid mucopolysaccharide which stained positively with alcian blue and metachromatically with toluidine blue. There was widespread fragmentation (Fig. 2c) and loss of elastic tissue with an increase in collagen fibres. Electron microscopy (Fig. 2d) confirmed these findings and pronounced vacuolisation of the medial smooth muscle cells was observed. Similar but less severe changes were seen in the remainder of the elastic pulmonary arteries, and in the smaller vessels the minimal branching of the elastic fibres suggested a persistence of fetal-type vasculature.

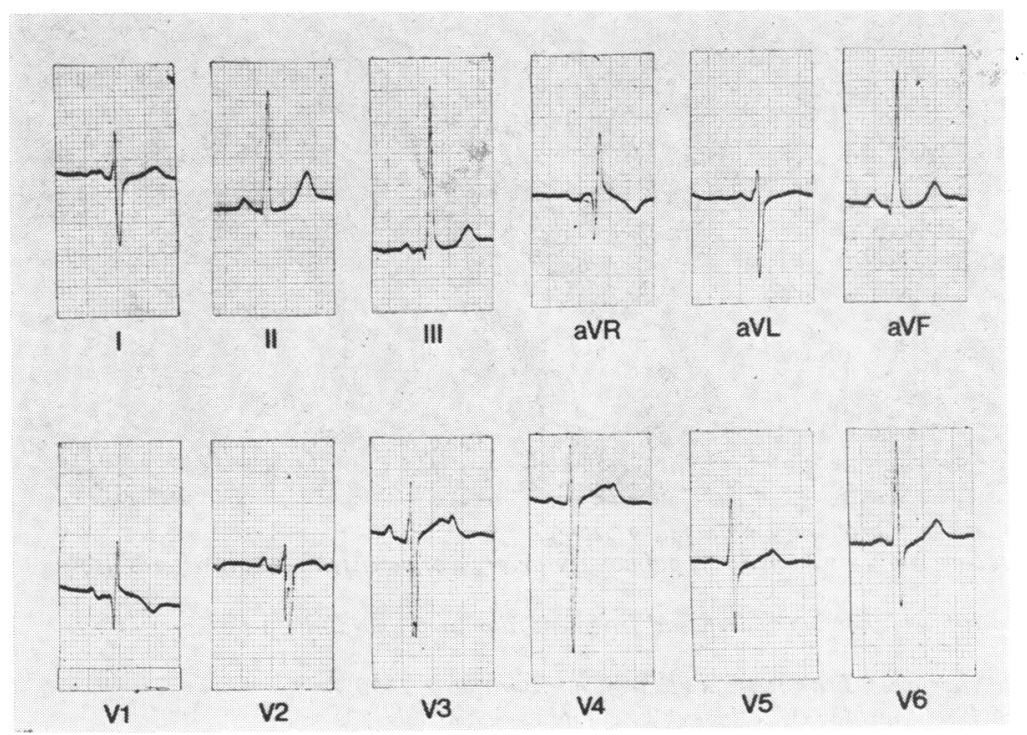

Fig. 1 Electrocardiogram (age 11) showing right ventricular hypertrophy. Calibration $1 \mathrm{~cm}=$ $1 \mathrm{mV}$ except $V 4$ and $V 5$ when $1 \mathrm{~cm}=2 \mathrm{mV}$. 


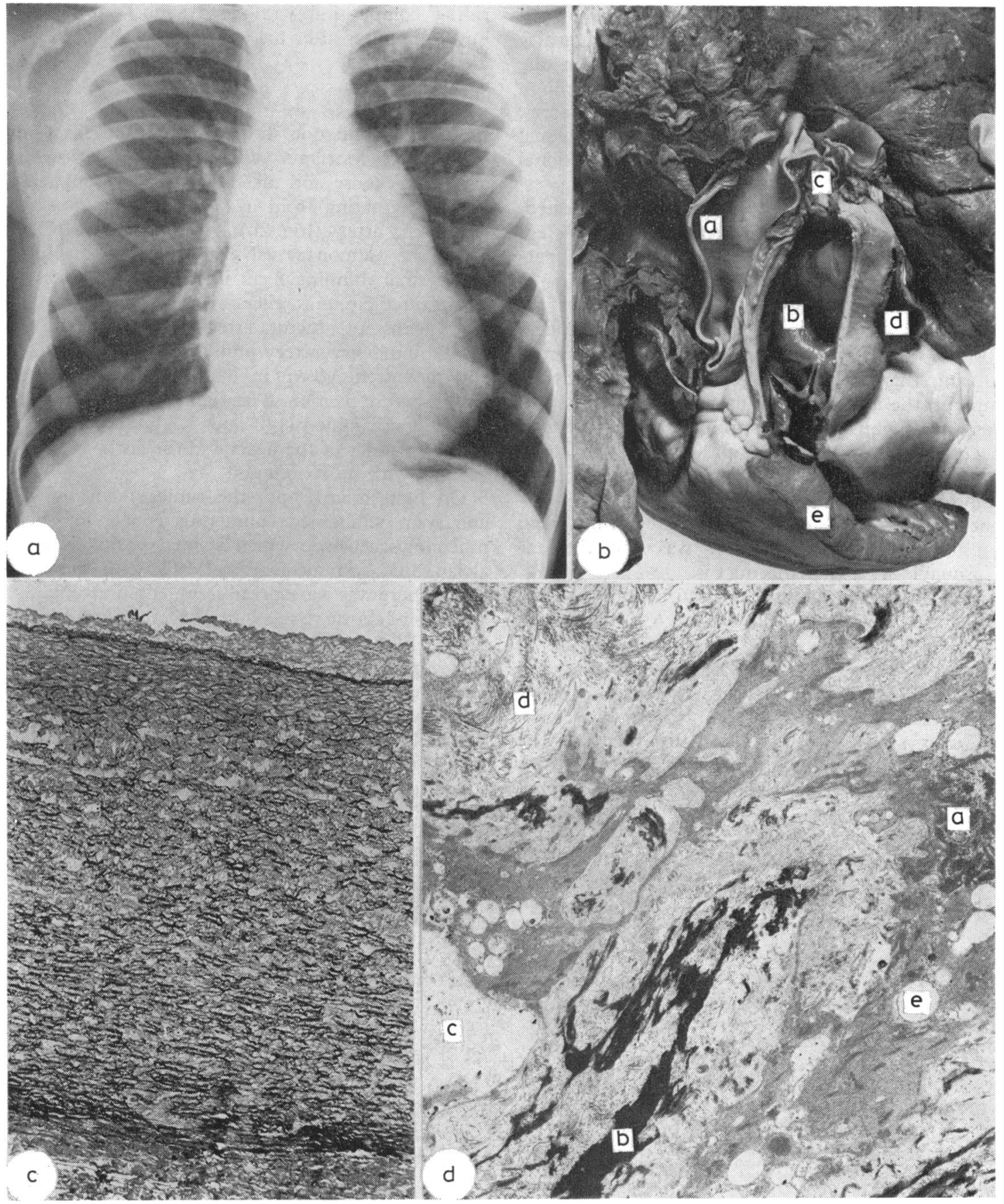

Fig. 2a Chest $\mathrm{x}$-ray film (age 11) showing a prominent pulmonary artery.

Fig. $2 \mathrm{~b}$ The heart and major vessels at necropsy. a, aorta; b, pulmonary artery; c, persistent ductus arteriosus; $\mathrm{d}$, site of rupture; $e$, right ventricle.

Fig. 2c Pulmonary artery adjacent to rupture showing widespread fragmentation of the medial elastic fibres.

(Elastic-van Giesson $\times 60$.)

Fig. 2d Pulmonary artery adjacent to rupture. (Transmission electron micrograph $\times 7500$.)

a, fibroblast; b, elastic tissue; c, mucopolysaccharide; d, collagen; e, cytoplasmic vacuole. 
The elastic pulmonary arteries showed focal intimal thickening but lipid was not demonstrated and there was no evidence of atheroma, syphilis, or infection. The muscular pulmonary arteries showed changes of severe pulmonary hypertension with severe medial hypertrophy, intimal thickening, and the development of longitudinal muscle bundles internal and external to the elastic lamina. Plexiform and angiomatoid lesions were not identified but many vessels were dilated and plentiful haemosiderin-laden macrophages were present within the alveoli.

The aorta was histologically normal.

\section{Discussion}

Aneurysm of the pulmonary artery trunk or its branches is uncommon. Boyd and McGavack ${ }^{1}$ have shown that a cardiac malformation with pulmonary hypertension is an aetiological factor in 40 per cent of such cases. Persistent ductus arteriosus is the commonest single lesion, occurring with 20 per cent of pulmonary aneurysms. The association of pulmonary hypertension with persistent ductus arteriosus is well recognised and not uncommonly mild dilatation of the pulmonary artery is observed. However, true aneurysm occurs in only 15 per cent, and a direct causative association with pulmonary hypertension is not always demonstrable. Other factors such as atheroma, endocarditis, tuberculosis, and syphilis contribute to the production of aneurysm in this condition.

In the patient described here, cystic medionecrosis was the main pathological change in the aneurysm and it is probable that this was a direct consequence of the extremely high pulmonary artery pressure. ${ }^{2}$ The presence of fetal-type pulmonary vessels, the absence of a significant leftto-right shunt, and the small size of the ductus offer support for the theory (discussed by Whitaker et $a .^{3}{ }^{3}$ ) that one cause of severe pulmonary hypertension associated with persistent ductus arteriosus may be a primary persistence of fetal pulmonary vasculature, rather than simply a consequence of increased pulmonary blood flow.

A predominantly systolic murmur is not an uncommon finding in persistent ductus arteriosus when pulmonary hypertension is present, ${ }^{3}$ and the intensity of the murmur in this patient possibly reflected the narrowness of the ductus. An unusual clinical feature was the lack of effort intolerance, and the absence of haemoptysis, despite the severity of the pulmonary hypertension.

Pulmonary artery aneurysms, especially of infective aetiology, may rupture into a bronchus or the pericardium. However, fatal rupture of an aneurysm associated with pure persistent ductus arteriosus is exceedingly rare and only six cases have been reported. Those described by Durno and Langdon Brown, and by Moench (cited in Lindert and Correll ${ }^{4}$ ) were associated with atheroma of the pulmonary artery and probable pulmonary hypertension; those reported by Hartwell and Tilden, and by d'Aunoy and van Haam (cited in Lindert and Correll ${ }^{4}$ ) were secondary to endocarditis and syphilis, respectively. Whether the cases published by Yuskis (cited in Lindert and Correll ${ }^{4}$ ) and by Lindert and Correll ${ }^{4}$ themselves were associated with pulmonary hypertension is unknown and histological study of the aneurysm was not performed. With the exception of the syphilitic case described by d'Aunoy and van Haam the ductus was always greater than $1 \mathrm{~cm}$ and the appearance, position, and size of the pulmonary aneurysm were variable.

Two cases are on record of patients with persistent ductus arteriosus and pulmonary hypertension dying from a ruptured pulmonary artery aneurysm secondary to cystic medionecrosis. One had coexistent cor biatriatum triloculare and aortic hypoplasia, ${ }^{5}$ and the other had mitral stenosis and cystic medionecrosis of the aorta. ${ }^{3}$

Ruptured pulmonary artery aneurysm associated with persistent ductus arteriosus and presenting as massive haemoptysis has, in one instance, been treated successfully by operation (de Camp, in Holman et al. ${ }^{6}$ ). It is therefore important that this complication should be considered in any patient with persistent ductus and pulmonary hypertension, especially if there are clinical features of pulmonary regurgitation.

We are grateful to Dr David Verel, consultant cardiologist, Sheffield Cardio-Thoracic Unit, Northern General Hospital, and to Dr H Pilling, HM Coroner for South Yorkshire, for kind permission to report this case. We also thank Professor M J Davies (St George's Hospital) and Dr P Carson (City General Hospital, Stoke-on-Trent) for helpful comments on this case.

\section{References}

1 Boyd LJ, McGavack TH. Aneurysm of the pulmonary artery. Am Heart $\mathcal{F} 1939$; 18: 562-78.

2 Spencer H. Pathology of the lung. 3rd ed. Oxford: Pergamon Press, 1977: 579-649.

3 Whitaker W, Heath D, Brown JW. Patent ductus arteriosus with pulmonary hypertension. Br Heart $\mathcal{f}$ 1955; 17: 121-37.

4 Lindert MCF, Correll HK. Rupture of pulmonary 
aneurysm accompanying patent ductus arteriosus. 6 Holman E, Gerbode F, Purdy A. The patent ductus. fAMA 1950; 143: 888-91.

5 Favorite GO. Cor biatriatum triloculare with rudimentary right ventricle, hypoplasia of transposed aorta and patent ductus arteriosus, terminating by rupture of dilated pulmonary artery. $\mathrm{Am} \mathcal{F} \mathrm{Med} S \mathrm{Sci}$ 1934; 187: 663-71.

f Thorac Surg 1953; 25: 111-42.

Requests for reprints to Dr David Slater, Department of Pathology, Floor E, University of Sheffield Medical School, Beech Hill Road, Sheffield S10 2RX. 